\title{
NOTES
}

\section{Polymerization of 1-[m-(Trimethylsilyl)phenyl]-1-propyne and Polymer Properties}

\author{
Kenji Tsuchinara, Tatsuya Oshita, Toshio Masuda, ${ }^{*}$ \\ and Toshinobu Higashimura* \\ Department of Polymer Chemistry, Kyoto University, \\ Kyoto 606, Japan
}

(Received March 14, 1991)

\begin{abstract}
KEY WORDS 1-[m-(Trimethylsilyl)phenyl]-1-propyne / Substituted Acetylene / Metathesis Polymerization / Transition-Metal Catalyst / SiliconContaining Polymer / Molecular-Weight Decrease / Gas Permeability /
\end{abstract}

Silicon-containing polyacetylenes often exhibit unique properties, especially high gas permeability. ${ }^{1,2}$ For example, poly[1-(trimethylsilyl)-1-propyne] [poly(TMSP)] shows the highest gas permeability among all the synthetic polymers, ${ }^{3}$ and has recently been under intensive research. ${ }^{4,5}$ Therefore, it is of interest to introduce trimethylsilyl group into the side chain of various polyacetylenes.

Disubstituted acetylenes are known to undergo metathesis polymerization with $\mathrm{Nb}$ and Ta catalysts. Among them, 1-phenyl-1propyne $^{6}(\mathrm{MeC} \equiv \mathrm{CPh} ; \mathrm{PhP})$ affords a polymer having a weight-average molecular weight $\left(\bar{M}_{w}\right)$ over $1 \times 10^{6}$. The polymer $[\operatorname{poly}(\mathrm{PhP})]$ is a white solid, which is soluble in many organic solvents and thermally fairly stable. It is one of the least gas-permeable polyacetylenes.

The present paper reports on the polymerization of 1-[m-(trimethylsilyl)phenyl]-1-propyne $\left(\mathrm{MeC} \equiv \mathrm{CC}_{6} \mathrm{H}_{4}-m-\mathrm{SiMe}_{3} ; m-\mathrm{Me}_{3} \mathrm{SiPhP}\right)$, a silicon-containing $\mathrm{PhP}$, and properties (especially, gas permeability) of the product polymer. We anticipated that the $o$-trimethylsilyl substituted PhP would not polymerize owing to too large a steric hindrance. Hence, the meta derivative, for which an appropriate steric effect is expected, was chosen as monomer. $m-\mathrm{Me}_{3} \mathrm{SiPhP}$ polymerized with $\mathrm{NbCl}_{5}$ to give a new, high molecular weight polymer in high yield. The polymer showed oxygen permeability $\left(P_{\mathrm{O}_{2}} 40 \times 10^{-10} \mathrm{~cm}^{3}\right.$ (STP). $\left.\mathrm{cm} \cdot \mathrm{cm}^{-2} \cdot \mathrm{s}^{-1} \cdot \mathrm{cmHg}^{-1}\right)$ higher than that of $\operatorname{poly}(\mathrm{PhP})\left(P_{\mathrm{O}_{2}}=6.3 \times 10^{-10} \mathrm{~cm}^{3}\right.$ (STP) . $\left.\mathrm{cm} \cdot \mathrm{cm}^{-2} \cdot \mathrm{s}^{-1} \cdot \mathrm{cmHg}^{-1}\right)$. The polymerization behavior and polymer properties of $m$ $\mathrm{Me}_{3} \mathrm{SiPhP}$ are compared with those of $\mathrm{PhP}$.

\section{EXPERIMENTAL}

The monomer, $m-\mathrm{Me}_{3} \mathrm{SiPhP}$, was prepared according to the following scheme with reference to the method of T.-L. Chang et al. ${ }^{7}$

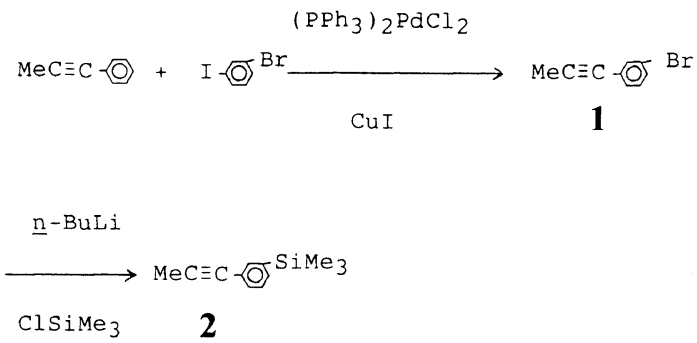

\section{1-(m-Bromophenyl)-1-propyne (1)}

After flushed with nitrogen, a 500-ml flask was charged with dry triethylamine $(150 \mathrm{ml})$, $\left(\mathrm{Ph}_{3} \mathrm{P}\right)_{2} \mathrm{PdCl}_{2}(0.84 \mathrm{~g}, 1.2 \mathrm{mmol}), \mathrm{Ph}_{3} \mathrm{P}(1.3 \mathrm{~g}$, $1.8 \mathrm{mmol}), \mathrm{CuI}(1.4 \mathrm{~g}, 7.2 \mathrm{mmol})$, and 1-bromo- 
3-iodobenzene $(15.3 \mathrm{ml}, 0.12 \mathrm{~mol})$. Then, propyne $(4.5 \mathrm{ml}, 0.24 \mathrm{~mol})$ was bubbled for $5 \mathrm{~min}$ into the mixture at $10^{\circ} \mathrm{C}$, and the mixture was stirred for $1 \mathrm{~h}$ at room temperature. The completion of the reaction was confirmed by gas chromatography (GC), and triethylamine was evaporated. Diethyl ether $(200 \mathrm{ml})$ was added, and insoluble salts were filtered off. The solution was washed with $5 \%$ hydrochloric acid and water. The organic phase was dried over anhydrous sodium sulfate overnight, ether was evaporated, and the product was distilled at reduced pressure; bp $90-92^{\circ} \mathrm{C} / 3 \mathrm{mmHg}$, yield $60 \%, d_{4}^{20} 1.384$.

\section{$m-\mathrm{Me}_{3} \mathrm{SiPhP}(2)$}

A 200-ml flask was flushed with dry nitrogen, and charged with a hexane solution of $n$-butyllithium $(62.5 \mathrm{ml}, 1.6 \mathrm{M}, 0.10 \mathrm{~mol})$. Part of the hexane $(\mathrm{ca} .40 \mathrm{ml})$ was evaporated with an aspirator under magnetic stirring. After the flask was cooled at $-20^{\circ} \mathrm{C}$, diethyl ether $(30 \mathrm{ml}$; dried over sodium) was gradually added at the same temperature, a solution of $1(14.1 \mathrm{ml}$, $0.10 \mathrm{~mol})$ in ether $(10 \mathrm{ml})$ was added dropwise, and the reaction mixture was left for $30 \mathrm{~min}$. Chlorotrimethylsilane $(12.7 \mathrm{ml}, 0.10 \mathrm{~mol})$ was gradually added at $-20^{\circ} \mathrm{C}$, and the mixture was allowed to stand at room temperature for $1 \mathrm{~h}$. After the completion of the reaction had been confirmed by GC, ice water $(50 \mathrm{ml})$ was added. The product was extracted with diethyl ether, washed with water, and dried over anhydrous sodium sulfate overnight. Diethyl ether was evaporated, and the product was distilled twice at reduced pressure from calcium hydride: bp $95^{\circ} \mathrm{C} / 3 \mathrm{mmHg}$, yield $45 \%$, purity $>99 \%$ (by GC); $d_{4}^{20} 0.899$.

Transition metal chlorides and organometallic cocatalysts were commercially obtained and used without further purification. Polymerizations were carried out under dry nitrogen in a way similar to $\mathrm{PhP},{ }^{6}$ i.e., in toluene at $80^{\circ} \mathrm{C},[\mathrm{M}]_{0}=0.50 \mathrm{M},[$ Cat $]=[$ Cocat $]=$ $10 \mathrm{mM}$ unless otherwise stated. Monomer conversions were determined by GC, and mo- lecular weights of polymers were determined by GPC (eluent, $\mathrm{CHCl}_{3}$ ) with use of a polystyrene calibration.

UV-visible spectra were recorded with a Shimadzu UV 190 spectrophotometer. Thermogravimetric analysis (TGA) was performed with a Shimadzu 20B thermal analyzer (heating rate $10^{\circ} \mathrm{C} \mathrm{min}^{-1}$ ). Gas permeability coefficients were measured with a K-315-N gas permeability apparatus (Rikaseiki Co., Japan); membrane thickness $\sim 50 \mu \mathrm{m}$.

\section{RESULTS AND DISCUSSION}

\section{Polymerization}

Table I shows results for the polymerization of $m-\mathrm{Me}_{3} \mathrm{SiPhP}$ by $\mathrm{TaCl}_{5}-$ and $\mathrm{NbCl}_{5}$-based catalysts. When $m$ - $\mathrm{Me}_{3} \mathrm{SiPhP}$ was polymerized with $\mathrm{NbCl}_{5}$ alone, this monomer was completely consumed to give a methanol-insoluble polymer in high yield. The weight-average

Table I. Polymerization of $m-\mathrm{Me}_{3} \mathrm{SiPhP}$ by various $\mathrm{Nb}$ and $\mathrm{Ta}$ catalysts ${ }^{\mathrm{a}}$

\begin{tabular}{|c|c|c|c|c|}
\hline \multirow[t]{2}{*}{ Cocat } & \multirow{2}{*}{$\frac{\text { Conversion }}{\%}$} & \multicolumn{3}{|c|}{ Polymer $^{b}$} \\
\hline & & Yield $/ \%$ & $\bar{M}_{w} / 10^{3 \mathrm{c}}$ & $\bar{M}_{n} / 10^{3 \mathrm{c}}$ \\
\hline \multicolumn{5}{|c|}{$\mathrm{NbCl}_{5}$-cocatalyst } \\
\hline none & 100 & 89 & 680 & 72 \\
\hline$n \mathrm{Bu}_{4} \mathrm{Sn}$ & 100 & $91^{\mathrm{d}}$ & - & - \\
\hline $\mathrm{Ph}_{4} \mathrm{Sn}$ & 100 & $93^{d}$ & - & - \\
\hline $\mathrm{Et}_{3} \mathrm{SiH}$ & 100 & $83^{d}$ & - & - \\
\hline $\mathrm{Ph}_{3} \mathrm{SiH}$ & 100 & $85^{\mathrm{d}}$ & - & - \\
\hline $\mathrm{Ph}_{3} \mathrm{Sb}$ & 100 & $100^{\mathrm{d}}$ & - & - \\
\hline $\mathrm{Ph}_{3} \mathrm{Bi}$ & 100 & $97^{d}$ & - & - \\
\hline \multicolumn{5}{|c|}{$\mathrm{TaCl}_{5}$-cocatalyst } \\
\hline none & 53 & 23 & 140 & 42 \\
\hline$n \mathrm{Bu}_{4} \mathrm{Sn}$ & 100 & $68^{d}$ & - & - \\
\hline $\mathrm{Ph}_{4} \mathrm{Sn}$ & 100 & 49 & 1000 & 170 \\
\hline $\mathrm{Et}_{3} \mathrm{SiH}$ & 79 & 52 & 220 & 56 \\
\hline $\mathrm{Ph}_{3} \mathrm{SiH}$ & 100 & 46 & 120 & 18 \\
\hline $\mathrm{Ph}_{3} \mathrm{Sb}$ & 60 & 38 & 350 & 170 \\
\hline $\mathrm{Ph}_{3} \mathrm{Bi}$ & 71 & 42 & 890 & 260 \\
\hline $\begin{array}{l}\text { a } \text { Polym } \\
0.50 \mathrm{M} \\
\text { b } \mathrm{MeOH} \\
\text { c Detern } \\
\text { d Partly }\end{array}$ & $\begin{array}{l}\text { rized in tolu } \\
{[\mathrm{Cat}]=[\mathrm{Coc}} \\
\text { insoluble par } \\
\text { ined by GPC. } \\
\text { nsoluble in C }\end{array}$ & $\begin{array}{l}\text { ne at } 80^{\circ} \\
\text { at }]=10 \mathrm{mN}\end{array}$ & $\begin{array}{l}\text { C for } 24 \\
\text { M. }\end{array}$ & ; $[\mathrm{M}]_{0}=$ \\
\hline
\end{tabular}


molecular weight $\left(\bar{M}_{w}\right)$ of the polymer reached $680 \times 10^{3}$, but the molecular weight distribution was broad. When organometallic cocatalysts, which are effective for the polymerization of $\mathrm{PhP}$, were used in conjunction with $\mathrm{NbCl}_{5}$, polymers were formed in high yields as well. The polymers were, however, partly insoluble in $\mathrm{CHCl}_{3}$. The tendency that $\mathrm{NbCl}_{5}$-cocatalyst systems produce insoluble polymers has been observed with 1-(trimethylsilyl)-1-propyne as well. ${ }^{8}$ This is probably because $\mathrm{NbCl}_{5}$ provide polymers having relatively high stereoregularity ${ }^{9}$ and further the use of a cocatalyst increases its molecular weight.

When $\mathrm{TaCl}_{5}$ alone was used as catalyst, the monomer conversion did not reach $100 \%$, and the polymer yield was considerably lower than that for $\mathrm{NbCl}_{5}$. Use of cocatalysts for $\mathrm{TaCl}_{5}$ was more or less effective in the increase of yield and $\bar{M}_{w}$ of polymer. $\mathrm{NbCl}_{5}$ alone, however, achieves a higher polymer yield than do these $\mathrm{TaCl}_{5}$-cocatalyst systems. The differences between monomer conversion and polymer yield were due to the formation of cyclotrimers.

When $\mathrm{PhP}$ is polymerized with $\mathrm{NbCl}_{5}$ or $\mathrm{TaCl}_{5}$ alone, the molecular weight of the polymer formed decreases after complete consumption of monomer. ${ }^{6}$ It is interesting whether this molecular weight decrease is prevented by the introduction of the bulky trimethylsilyl group into meta position. Thus, time course of the polymerization was studied using the $\mathrm{NbCl}_{5}$ catalyst which achieves a high polymer yield (Figure 1). The monomer conversion reached $100 \%$ after $6 \mathrm{~h}$. The reaction rate is smaller than that of $\mathrm{PhP}$ (the polymerization of $\mathrm{PhP}$ proceeded completely within $2 \mathrm{~h})$. The $\bar{M}_{w}$ of polymer was $\sim 600 \times 10^{3}$ after $6 \mathrm{~h}$, which was maintained even after $24 \mathrm{~h}$. Thus, it is possible to restrain the decrease of molecular weight by increasing bulkiness of the substituent.

As seen in Figure 1, the $\bar{M}_{w}$ of polymer increased approximately in proportion to monomer conversion. This indicates the presence

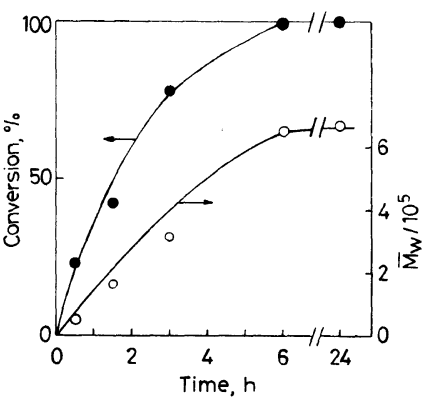

Figure 1. Time course of the polymerization of $\mathrm{m}$ $\mathrm{Me}_{3} \mathrm{SiPhP}$ by $\mathrm{NbCl}_{5}$ (in toluene, $80^{\circ} \mathrm{C} ;[\mathrm{M}]_{0}=0.50 \mathrm{M}$; $\left.\left[\mathrm{NbCl}_{5}\right]=10 \mathrm{mM}\right)$.

Table II. Solvent effects on the polymerization of $m-\mathrm{Me}_{3} \mathrm{SiPhP}$ by $\mathrm{NbCl}_{5}{ }^{\mathrm{a}}$

\begin{tabular}{lccccc} 
& \multicolumn{2}{c}{ Conversion } & \multicolumn{3}{c}{ Polymer $^{\mathrm{b}}$} \\
\cline { 2 - 3 } \cline { 5 - 6 } Solvent & $\%$ & & Yield $/ \%$ & $\bar{M}_{w} / 10^{3 \mathrm{c}}$ & $\bar{M}_{n} / 10^{3 \mathrm{c}}$ \\
\cline { 5 - 6 } & 100 & & 89 & 680 & 72 \\
Toluene & 100 & & $75^{\mathrm{d}}$ & - & - \\
$\mathrm{CCl}_{4}$ & 66 & & 37 & 100 & 30 \\
$\left(\mathrm{CH}_{2} \mathrm{Cl}\right)_{2}$ & 100 & & 73 & 440 & 93 \\
Anisole & 100 & & 72 & 360 & 88 \\
\hline
\end{tabular}

a Polymerized in toluene at $80^{\circ} \mathrm{C}$ for $24 \mathrm{~h}$; [M] $]_{0}=$ $0.50 \mathrm{M},\left[\mathrm{NbCl}_{5}\right]=10 \mathrm{mM}$.

b $\mathrm{MeOH}$-insoluble part.

c Determined by GPC.

d Partly insoluble in $\mathrm{CHCl}_{3}$.

of a long-lived propagating species. Such a tendency was seen also in the polymerization of 1-phenyl-1-alkynes by $\mathrm{NbCl}_{5}$ and $\mathrm{TaCl}_{5}{ }^{6}$

Solvent effects on the polymerization by $\mathrm{NbCl}_{5}$ were studied (Table II). High-molecular-weight polymers were obtained in good yields not only in hydrocarbon solvents but also in chlorine-containing solvents and anisole.

In order to know the relative monomer reactivity in the propagation reaction, copolymerization of $m-\mathrm{Me}_{3} \mathrm{SiPhP}$ with $\mathrm{PhP}$ was attempted in toluene solution at $80^{\circ} \mathrm{C} ;\left[\mathrm{M}_{1}\right]_{0}=$ $\left[\mathrm{M}_{2}\right]_{0}=0.25 \mathrm{M},\left[\mathrm{NbCl}_{5}\right]=20 \mathrm{mM}$. Both monomers reacted virtually at the same rate (relative rate, $m-\mathrm{Me}_{3} \mathrm{SiPhP}: \mathrm{PhP}=0.9: 1$ ). Further, $m-\mathrm{Me}_{3} \mathrm{SiPhP}$ was more reactive than 
1 -( $m$-bromophenyl)-1-propyne $(m-\mathrm{BrPhP})$ in their copolymerization (relative rate, $m$ $\left.\mathrm{Me}_{3} \mathrm{SiPhP}: m-\mathrm{BrPhP}=2: 1\right)$. In general, the relative monomer reactivity in copolymerization is determined by steric and electronic effects; i.e., it increases with decreasing bulkiness of substituent and with increasing electron-donating ability of substituent. ${ }^{10,11}$ Consequently, the similar reactivities of $\mathrm{PhP}$ and $m-\mathrm{Me}_{3} \mathrm{SiPhP}$ are attributable to compensation of the steric and electronic effects in the latter monomer.

\section{Structure and Properties of the Polymer}

The structure and properties were studied by using the poly $\left(m-\mathrm{Me}_{3} \mathrm{SiPhP}\right)$ obtained with $\mathrm{NbCl}_{5}$ alone in Table I.

The elemental analysis values for the polymer agreed well with the ones calculated for the polymerization product; Anal. Calcd for $\left(\mathrm{C}_{12} \mathrm{H}_{16} \mathrm{Si}\right)_{n}: \mathrm{C}, 76.6 \% ; \mathrm{H}, 8.5 \% ; \mathrm{Si}, 14.9 \%$; Found: C, $76.9 \% ; \mathrm{H}, 8.3 \% ; \mathrm{Si}, 14.9 \%$.

The IR spectrum of poly $\left(m-\mathrm{Me}_{3} \mathrm{SiPhP}\right)$ showed no signal characteristic of the $\mathrm{C} \equiv \mathrm{C}$ stretching $\left(2200 \mathrm{~cm}^{-1}\right)$ seen in the monomer. Instead, an absorption assignable to the $\mathrm{C}=\mathrm{C}$ stretching appeared at $\sim 1580 \mathrm{~cm}^{-1}$ (w). Furthermore, no signals due to acetylenic carbons were observed in the ${ }^{13} \mathrm{C}$ NMR spectrum of poly $\left(m-\mathrm{Me}_{3} \mathrm{SiPhP}\right)$. These analytical and spectral data are compatible with the polymer structure of $+\mathrm{CMe}=\mathrm{CC}_{6} \mathrm{H}_{4}-m$ $\left.\mathrm{SiMe}_{3}\right)_{n}$.

$\operatorname{Poly}\left(m-\mathrm{Me}_{3} \mathrm{SiPhP}\right)$ is a novel polymer with the form of white solid. The solubility of the polymer is as follows: completely soluble in toluene, cyclohexane, $\mathrm{CCl}_{4}, \mathrm{CHCl}_{3}$ and anisole; partly soluble in $n$-hexane, diethyl ether and tetrahydrofuran; and insoluble in $\left(\mathrm{CH}_{2} \mathrm{Cl}\right)_{2}$, 1,4-dioxane, acetone, acetophenone, ethyl acetate, methyl benzoate, nitrobenzene, and acetonitrile. A tough film could be obtained by casting the polymer from toluene solution.

Figure 2 shows UV-visible spectra of $\operatorname{poly}\left(m-\mathrm{Me}_{3} \mathrm{SiPhP}\right)$ and poly(PhP). The ab-

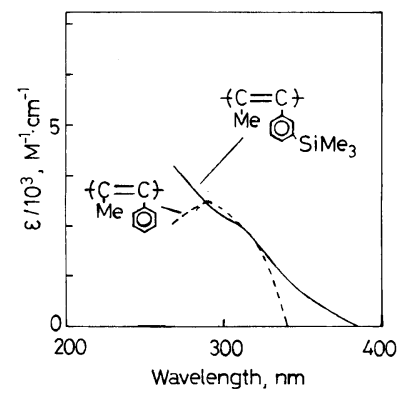

Figure 2. UV-visible spectra of poly(1-phenyl-1propynes) (measured in cyclohexane).

Table III. Gas permeability of poly(1-phenyl-1-propynes)

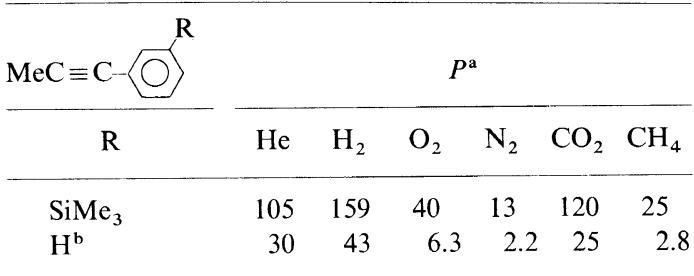

a Gas permeability coefficient in the units of $1 \times 10^{-10}$ $\mathrm{cm}^{3}(\mathrm{STP}) \cdot \mathrm{cm} /\left(\mathrm{cm}^{2} \cdot \mathrm{s} \cdot \mathrm{cmHg}\right)$ at $25^{\circ} \mathrm{C}$.

${ }^{b}$ Data from ref 10.

sorption of poly $\left(m-\mathrm{Me}_{3} \mathrm{SiPhP}\right)$ appears only below $400 \mathrm{~nm}$, i.e., in the ultraviolet region, which corresponds to the fact that $\operatorname{poly}(m-$ $\left.\mathrm{Me}_{3} \mathrm{SiPhP}\right)$ is a white solid. The absorption pattern resemble that of poly $(\mathrm{PhP})$, although a minor difference is seen in the $350-400 \mathrm{~nm}$ region.

In the TGA measurement in air, $\operatorname{poly}(m-$ $\mathrm{Me}_{3} \mathrm{SiPhP}$ ) began to lose weight at $310^{\circ} \mathrm{C}$, whereas poly $(\mathrm{PhP})$ did at $280^{\circ} \mathrm{C}$; i.e., introduction of trimethylsilyl group somewhat increased thermal stability. Even after the poly $\left(m-\mathrm{Me}_{3} \mathrm{SiPhP}\right)$ had been heated at $120^{\circ} \mathrm{C}$ for $20 \mathrm{~h}$ in air, no molecular-weight change was observed. Thus, poly $\left(m-\mathrm{Me}_{3} \mathrm{SiPhP}\right)$ turns out thermally fairly stable among substituted polyacetylenes.

The gas permeability of a poly $\left(m-\mathrm{Me}_{3} \mathrm{SiPhP}\right)$ membrane was studied by using the polymer sample with the highest molecular weight (cat: $\mathrm{TaCl}_{5}-\mathrm{Ph}_{3} \mathrm{Bi}$ ). The permeability coefficients of 
Table IV. Comparison of poly $\left(m-\mathrm{Me}_{3} \mathrm{SiPhP}\right)$ with poly(PhP)

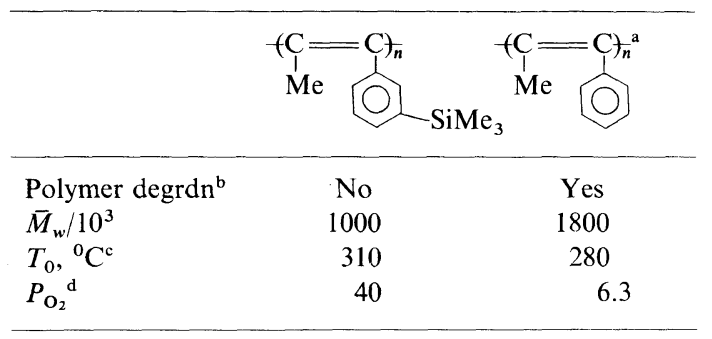

a Data from ref 6 and 10.

b Molecular-weight decrease after the polymerization by $\mathrm{NbCl}_{5}$ or $\mathrm{TaCl}_{5}$ is completed.

c Temperature at which weight loss starts in air.

${ }^{d}$ Oxygen permeability coefficient in the units of $1 \times 10^{-10} \mathrm{~cm}^{3}(\mathrm{STP}) \cdot \mathrm{cm} /\left(\mathrm{cm}^{2} \cdot \mathrm{s} \cdot \mathrm{cmHg}\right)$ at $25^{\circ} \mathrm{C}$.

poly $\left(m-\mathrm{Me}_{3} \mathrm{SiPhP}\right)$ were 3-10 times as large as those of poly $(\mathrm{PhP})$ for all the gases examined (Table III). Thus, gas permeability is enhanced by the introduction of trimethylsilyl group. The gas permeability of poly $\left(m-\mathrm{Me}_{3} \mathrm{SiPhP}\right)$, however, is medium among those of various substituted polyacetylenes. ${ }^{12}$

\section{Comparison with PhP}

In Table IV, the polymerization behavior and polymer properties of $m-\mathrm{Me}_{3} \mathrm{SiPhP}$ are compared with those of PhP:

i) In the polymerization of $\mathrm{PhP}$ by $\mathrm{NbCl}_{5}$ and $\mathrm{TaCl}_{5}$, the molecular weight of polymer decreases after the monomer has been completely consumed. In contrast, no decrease in molecular weight occurred in the case of $m-\mathrm{Me}_{3} \mathrm{SiPhP}$. This is explained by an idea that the bulky trimethylsilyl group inhibits the attack (back-biting) of the main chain by the propagating species.

ii) The molecular weight of $\operatorname{poly}\left(m-\mathrm{Me}_{3}-\right.$ $\mathrm{SiPhP}$ ) reached $1 \times 10^{6}$, which is slighly lower than that of poly $(\mathrm{PhP})$. Thus, trimethylsilyl group at meta position of PhP does not affect very much the molecular weight of the polymer formed.

iii) Though poly $\left(m-\mathrm{Me}_{3} \mathrm{SiPhP}\right) \mathrm{s}$ obtained with $\mathrm{NbCl}_{5}$ alone and $\mathrm{TaCl}_{5}$-cocatalyst systems were soluble in various organic solvents, the polymers formed with $\mathrm{NbCl}_{5}$-cocatalyst systems were insoluble. In contrast, poly (PhP) is soluble in many organic solvents irrespective of the kind of catalyst. This difference seems due to the lower flexibility of the more sterically crowded poly $\left(m-\mathrm{Me}_{3} \mathrm{SiPhP}\right)$.

iv) The thermal stability of $\operatorname{poly}\left(m-\mathrm{Me}_{3}-\right.$ $\mathrm{SiPhP})$ did not greatly differ from that of poly $(\mathrm{PhP})$. It is, however, noted that these polymers are thermally more stable than sterically less crowded polymers such as poly(2-alkynes).

v) $\operatorname{Poly}(\mathrm{PhP})$ is one of the substituted polyacetylenes that show the lowest gas permeability. ${ }^{12}$ The oxygen permeability coefficient of poly $\left(m-\mathrm{Me}_{3} \mathrm{SiPhP}\right)$ was one order of magnitude larger than that of poly $(\mathrm{PhP})$. This conforms with the general tendency that silicon-containing polyacetylenes exhibit high oxygen permeability.

Acknowledgment. We thank Dr. K. Tamao for helpful discussions on monomer synthesis. This research was partly supported by the Grant-in-Aid for Scientific Research on Priority Areas "New Functionality Materials" from the Ministry of Education, Science, and Culture of Japan.

\section{REFERENCES}

1. T. Masuda and T. Higashimura, Adv. Chem. Ser., No. 224, (1990), Chapter 35.

2. G. Costa, in "Comprehensive Polymer Science," Vol. 4, G. Allen, Ed., Pergamon, New York, 1989, Chapter 9.

3. T. Masuda, E. Isobe, T. Higashimura, and $\mathrm{K}$. Takada, J. Am. Chem. Soc., 105, 7473 (1983).

4. Y. Ichiraku, S. A. Stern, and T. Nakagawa, J. Membrane Sci., 34, 5 (1987).

5. M. Langsam, M. Anand, and E. J. Karwacki, Gas Sep. Purification, 2, 3 (1988).

6. T. Masuda, T. Takahashi, and T. Higashimura, Macromolecules, 18, 312 (1985).

7. T.-L. Chang, L. J. Holzknecht, H. B. Mark, Jr., T. H. Ridgway, and H. Zimmer, J. Polym. Sci., A, Polym. Chem. Ed., 27, 989 (1989).

8. T. Masuda, E. Isobe, T. Hamano, and T. Higashimura, Macromolecules, 19, 2448 (1986). 


\section{K. Tsuchihara et al.}

9. H. Izumikawa, T. Masuda, and T. Higashimura, Polym. Bull., in press.

10. K. Hasegawa, T. Masuda, and T. Higashimura, Macromolecules, 8, 255 (1975).
11. T. Hamano, T. Masuda, and T. Higashimura, $J$. Polym. Sci., A, Polym. Chem. Ed., 26, 2603 (1988).

12. T. Masuda, Y. Iguchi, B.-Z. Tang, and T. Higashimura, Polymer, 29, 2041 (1988). 